\title{
Case Reports in Nephrology and Dialysis
}

\section{The Unpredictability of Idiopathic Membranous Nephropathy: An Illustrative Case Report}

\author{
Murray L. Levin Shubhada Ahya \\ Division of Nephrology/Hypertension, Department of Medicine, Northwestern University \\ Feinberg School of Medicine and Northwestern Memorial Hospital, Chicago, IL, USA
}

\section{Keywords}

Membranous nephropathy $\cdot$ Immunosuppression $\cdot$ Recurrent disease

\begin{abstract}
The case of a female patient with primary membranous nephropathy is presented. She was treated with corticosteroids and chlorambucil after conservative therapy had failed and went into remission for 5 years. Her nephrotic syndrome recurred but did not respond to the same regimen. She had another complete remission after treatment with corticosteroids and cyclosporine, but the nephrosis recurred after 7 years. Again, she failed to respond with retreatment of steroids plus cyclosporine. She was treated with alternate-day steroid plus mycophenolate and, once again, had a complete remission. She was maintained on low-dose mycophenolate for 7 more years. The mycophenolate had to be discontinued because of cytomegalovirus colitis. Treatment with ganciclovir abolished the colitis. She is still in remission 10 years later. The case is discussed with regard to current knowledge of the immune pathogenesis of membranous nephropathy as well as the unknowns of the immunogenesis of the disease.
\end{abstract}

(C) 2018 The Author(s)

Published by S. Karger AG, Basel 


\section{Case Reports in Nephrology and Dialysis}

\section{Introduction}

The pathogenesis of idiopathic membranous nephropathy has undergone significantly greater understanding over the past decade since the description of antibodies to the phospholipase A2 receptor on the basement membrane of glomeruli from about $70 \%$ of patients with primary membranous disease [1]. Subsequently, an additional $5-10 \%$ of patients were found to have antibodies to thrombospondin type 1 domain-containing 7A [2]. Thus, the description of precise circulating antibodies on the glomerular basement membranes of $75 \%$ or more of patients with primary idiopathic membranous nephropathy has provided significant insight into the pathogenesis of the disease.

However, the genesis of these antibodies remains unknown. The antibodies are, then, secondary phenomena whose causes require elucidation. Because of the lack of primary causation for membranous nephropathy, treatment remains empirical although much more efficacious than several decades ago. Current pathogenetic theories and therapeutic approaches were summarized in two extensive reviews published recently [3, 4]. The following case gives evidence to the empiric nature of the current state of therapeutic interventions.

\section{Case Report}

The patient is currently a 93-year-old female who was first referred to us at age 64 because of edema involving both legs to the thighs and above, and $12 \mathrm{~g}$ of proteinuria in $24 \mathrm{~h}$. Her renal function was within normal limits. The creatinine clearance was $80 \mathrm{~mL} / \mathrm{min}$, her BUN was $14 \mathrm{mg} / \mathrm{dL}$, and her serum creatinine was $0.9 \mathrm{mg} / \mathrm{dL}$. Her serum albumin was 1.1 $\mathrm{mg} / \mathrm{dL}$. Her total serum cholesterol was greater than $300 \mathrm{mg} / \mathrm{dL}$. Repeat 24 -h proteinuria was $13 \mathrm{~g}$. A renal biopsy was classic for membranous nephropathy by light, immuno-, and electron microscopy criteria. No malignancies were discovered, and tests for systemic lupus and other collagen diseases were negative. She was seronegative for human immunodeficiency virus and hepatitis B and C. She had never received gold salts, nor did she take nonsteroidal antiinflammatory drugs. Thus, she had idiopathic membranous nephropathy by clinical criteria.

A conservative trial of furosemide and an angiotensin enzyme inhibitor was attempted with no reduction in her proteinuria. She became orthostatic when the dose of furosemide was increased in an attempt to relieve her symptoms of leg stiffness and difficulty with ambulation. She remained weak and relatively immobilized.

After 4 months of the above treatment, she was treated with the steroid and chlorambucil protocol described by Ponticelli et al. [5, 6]. There was no response for 2 months, but her serum albumin began to rise to $2 \mathrm{mg} / \mathrm{dL}$ by month 3. Her 24-h albumin excretion continued to be $10 \mathrm{mg} / 24 \mathrm{~h}$. By month 4, her albuminuria was no longer present. Her 24-h protein excretion had fallen to less than $100 \mathrm{mg}$. She completed the full 6-month course and remained in complete remission for 5 years. There was no proteinuria, and all blood chemistries remained within normal limits.

Five years after her complete remission, the nephrotic syndrome recurred with edema, proteinuria, hyperlipidemia, etc. The therapy was repeated for the 6-month course of alternating prednisone and chlorambucil exactly as administered previously, but there was no response. Two months later, a course of intravenous immunoglobulin [7] was attempted with a 2 -month induction period and 4 months of infusions every 3 weeks with no effect on her proteinuria. This protocol was terminated at the patient's request because she had lost patience. 


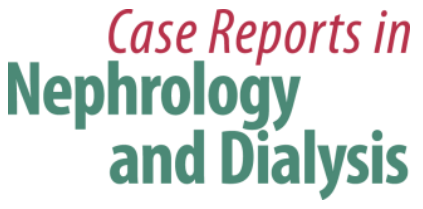

Case Rep Nephrol Dial 2018;8:103-106

DOI: $10.1159 / 000489773$

(c) 2018 The Author(s). Published by S. Karger AG, Basel www.karger.com/cnd

Levin and Ahya: The Unpredictability of Idiopathic Membranous Nephropathy: An Illustrative Case Report

She was then treated with $20 \mathrm{mg}$ of prednisone on alternate days plus cyclosporine $4 \mathrm{mg} / \mathrm{kg}$ daily [8]. Within 3 months, she was in complete remission. Her dose of prednisone was tapered to 0 by 6 months, and her dose of cyclosporine was reduced to $25 \mathrm{mg}$ daily.

She remained in remission for another 7 years, but her nephrotic syndrome again recurred. The prednisone/cyclosporine regimen was repeated for 6 months with no response. She was then treated with alternate-day prednisone as before plus mycophenolate $500 \mathrm{mg}$ twice daily [9]. Once again, she had a complete remission after 3 months.

The steroids were tapered to 0 after 6 months, and the mycophenolate was continued at $125 \mathrm{mg}$ twice daily. She remained in complete remission until 7 years later when she developed cytomegalovirus colitis that remitted upon discontinuation of the mycophenolate and treatment with ganciclovir. She remains in complete remission 10 years later on no treatment.

\section{Discussion}

The patient described demonstrated complete therapeutic responses to two immunosuppressive regimens, only to encounter recurrences after each. She failed to respond to repeat courses of both therapeutic treatments. She then responded to a third regimen. She was not followed with measurements of antibodies to phospholipase A2 receptor or to thrombospondin type 1 domain-containing 7A simply because such antibodies had not yet been described at the time she was treated.

It is unlikely that these remissions occurred spontaneously as described by Gluck et al. [10] because her remissions occurred only after the therapeutic regimens described. Although the remissions might have been fortuitously spontaneous, that explanation seems unlikely because of the time course of three separate episodes that did not remit without therapy and the fact that there were two recurrences that did not respond to previous therapy.

Multiple questions result from this patient's complex clinical course:

- Even if she did develop her disease as the result of an immune response, what triggered the response?

- Why did she respond to two immunosuppressive regimens and then fail to respond to both when her disease recurred?

- Why did a low-dose steroid plus mycophenolate regimen induce a long-standing remission that continues to the present time when neither of the other two regimens caused such an enduring response?

Because the trigger that induced her disease is unknown, and why she altered her response to therapy is also unknown, the answers to these questions remain unknown as well. It is certainly possible that there were several different stimuli to her immune system that caused her disease and different responses to therapy. What her course does demonstrate is that the development of idiopathic membranous nephropathy is an epiphenomenon caused by either endogenous or exogenous stimuli that induce the development of antibodies to the two known antigens, and perhaps to more, and that such responses and/or responses to therapy can change dramatically. It is possible that she experienced new first or second "hits" that caused her recurrences or that the clones that synthesized her probable antibodies were altered because of epigenetic changes that rendered her unresponsive to the steroid plus chlorambucil and steroid plus cyclosporine treatments.

Future research may determine the nature of the stimuli that induce the immune response(s) or change the clonal receptiveness to various therapeutic efforts so that more targeted and precise therapeutic approaches can be developed. Until then, patients will continue 


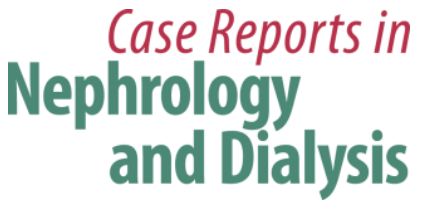

to be treated with powerful, frequently effective but nonspecific treatments that carry considerable actual and potential toxicities.

\section{Acknowledgements}

No funding was involved in this case report.

\section{Statement of Ethics}

The patient was aware of potential complications of each therapeutic intervention before therapy was initiated. She gave verbal consent since each intervention was established in clinical practice and the literature. Therefore, nothing investigative occurred.

\section{Disclosure Statement}

The authors declare that there is no conflict of interest.

\section{References}

1 Beck LH Jr, Bonegio RG, Lambeau G, Beck DM, Powell DW, Cummins TD et al. M-type phospholipase A2 receptor as target antigen in idiopathic membranous nephropathy. N Engl J Med. 2009 Jul;361(1):11-21.

2 Tomas NM, Beck LH Jr, Meyer-Schwesinger C, Seitz-Polski B, Ma H, Zahner G et al. Thrombospondin type-1 domain-containing 7A in idiopathic membranous nephropathy. N Engl J Med. 2014 Dec;371(24):2277-87.

3 Couser WG. Primary Membranous Nephropathy. Clin J Am Soc Nephrol. 2017 Jun;12 (6):983-97.

4 Cattran DC, Brenchley PE. Membranous nephropathy: integrating basic science into improved clinical management. Kidney Int. 2017 Mar;91(3):566-74.

5 Ponticelli C, Zucchelli P, Imbasciati E, Cagnoli L, Pozzi C, Passerini P et al. Controlled trial of methylprednisolone and chlorambucil in idiopathic membranous nephropathy. N Engl J Med. 1984 Apr;310(15):946-50.

6 Ponticelli C, Zucchelli P, Passerini P, Cagnoli L, Cesana B, Pozzi C et al. A randomized trial of methylprednisolone and chlorambucil in idiopathic membranous nephropathy. N Engl J Med. 1989 Jan;320(1):8-13.

7 Palla R, Cirami C, Panichi V, Bianchi AM, Parrini M, Grazi G. Intravenous immunoglobulin therapy of membranous nephropathy: efficacy and safety. Clin Nephrol. 1991 Mar;35(3):98-104.

8 Rostoker G, Belghiti D, Ben Maadi A, Rémy P, Lang P, Weil B et al. Long-term cyclosporin A therapy for severe idiopathic membranous nephropathy. Nephron. 1993;63(3):335-41.

9 Miller G, Zimmerman R 3rd, Radhakrishnan J, Appel G. Use of mycophenolate mofetil in resistant membranous nephropathy. Am J Kidney Dis. 2000 Aug;36(2):250-6.

10 Gluck MC, Gallo G, Lowenstein J, Baldwin DS. Membranous glomerulonephritis. Evolution of clinical and pathologic features. Ann Intern Med. 1973 Jan;78(1):1-12. 